\title{
Environmental Enrichment Increases the GFAP + Stem Cell Pool and Reverses Hypoxia-Induced Cognitive Deficits in Juvenile Mice
}

\author{
Natalina Salmaso, ${ }^{1}$ John Silbereis, ${ }^{1}$ Mila Komitova, ${ }^{1}$ Patrick Mitchell, ${ }^{1}$ Katherine Chapman, ${ }^{1}$ Laura R. Ment ${ }^{2}$ \\ Michael L. Schwartz, ${ }^{3}$ and Flora M. Vaccarino ${ }^{1,3}$ \\ ${ }^{1}$ Child Study Center and Departments of ${ }^{2}$ Pediatrics and ${ }^{3}$ Neurobiology, Yale University School of Medicine, New Haven, Connecticut 06520
}

Premature children born with very low birth weight (VLBW) can suffer chronic hypoxic injury as a consequence of abnormal lung development and cardiovascular abnormalities, often leading to grave neurological and behavioral consequences. Emerging evidence suggests that environmental enrichment improves outcome in animal models of adult brain injury and disease; however, little is known about the impact of environmental enrichment following developmental brain injury. Intriguingly, data on socio-demographic factors from longitudinal studies that examined a number of VLBW cohorts suggest that early environment has a substantial impact on neurological and behavioral outcomes. In the current study, we demonstrate that environmental enrichment significantly enhances behavioral and neurobiological recovery from perinatal hypoxic injury. Using a genetic fate-mapping model that allows us to trace the progeny of GFAP + astroglial cells, we show that hypoxic injury increases the proportion of astroglial cells that attain a neuronal fate. In contrast, environmental enrichment increases the stem cell pool, both through increased stem cell proliferation and stem cell survival. In mice subjected to hypoxia and subsequent enrichment there is an additive effect of both conditions on hippocampal neurogenesis from astroglia, resulting in a robust increase in the number of neurons arising from GFAP + cells by the time these mice reach full adulthood.

\section{Introduction}

Approximately $1 \%$ of children born in the United States are premature and born at a very low birth weight (VLBW). Clinically, VLBW children exhibit a range of neurological and behavioral disturbances, including decreased brain volume, white matter abnormalities, and developmental delays. These perturbations are thought to be a consequence of chronic hypoxic injury due to immature lung development. Remarkably, a substantial portion of VLBW children are able to recover from these abnormalities over time, and some of them attain normal cognitive function by the time they reach early adulthood (Saigal and Doyle, 2008; Luu et al., 2011). However, the factors that contribute to heterogeneity in long-term outcomes are not known. The current study attempts to elucidate the underlying cellular mechanisms by using a mouse model of perinatal hypoxia that mimics the injury and recovery observed in VLBW children.

\footnotetext{
Received March 19, 2012; revised April 26, 2012; accepted May 7, 2012

Author contributions: N.S., J.S., M.K., L.R.M., M.L.S., and F.M.V. designed research; N.S., J.S., M.K., P.M., and K.C. performed research; N.S., J.S., and F.M.V. analyzed data; N.S. and F.M.V. wrote the paper.

This work was funded by NIH Grants P01 NS062686 and R21 AG034495 to F.M.V., a PSD2 Fellowship from the Fonds de recherché en santé du Quebec to N.S, and a Swedish Brain Foundation (Hjarnfonden) and a Swedish Medical Association fellowship to M.K. We acknowledge Teresa Sandoval-Minero, Eylem Ocal, Ellen Hoffman, Lauren Provini, Devon Fagel, and Allyson Vermaak for technical assistance and useful discussions. We thank Dr. David Mumby for his advice on alternatives to testing a traditional Morris water maze paradigm. We thank Drs. Charles Stiles and John Alberta, Dana-Farber Cancer Institute, Boston, MA, for their gift of the Olig2 antibody.

The authors declare no competing financial interests.

Correspondence should be addressed to Flora Vaccarino, Child Study Center, 230 South Frontage Road, New Haven, CT 06520. E-mail: flora.vaccarino@yale.edu.

DOI:10.1523/JNEUROSCI.1398-12.2012

Copyright $\odot 2012$ the authors $\quad 0270-6474 / 12 / 328930-10 \$ 15.00 / 0$
}

Emerging evidence suggests that various types of injury, such as hypoxic and/or ischemic insults, induce strong proliferative and neurogenic/gliogenic responses in the subgranular zone of the hippocampal dentate gyrus (DG), a postnatal neurogenic niche (Kuhn et al., 2001; Sharp et al., 2002; Parent, 2003; Fagel et al., 2006; Yang and Levison, 2006; Kernie and Parent, 2010). In the postnatal brain, neural stem cells (NSCs) are a subset of glial fibrillary acidic protein (GFAP)-expressing astrocytes (Doetsch et al., 1999; Seki and Arai, 1999; Seri et al., 2001; Alvarez-Buylla et al., 2002; Filippov et al., 2003; Imura et al., 2003; Garcia et al., 2004). Neural stem cells give rise to transient-amplifying progenitors that express neuronal lineage makers and generate new neurons throughout life (Belachew et al., 2003; Hack et al., 2005; Hevner et al., 2006; Brill et al., 2008; Rivers et al., 2008).

To study the cellular and molecular mechanisms that confer higher inherent plasticity to the DG, allowing for a more adaptive response to brain injury, we investigated the fate of GFAP + astroglia in the DG by tagging these cells with heritable reporter genes via tamoxifen-inducible Cre recombinase in GFAP$\underline{C r e E R}^{\mathrm{T} 2}$ (GCE) transgenic mice. In addition, because environmental enrichment with exercise has been demonstrated to increase hippocampal neurogenesis in adulthood (Kempermann et al., 1997; van Praag et al., 1999a; Olson et al., 2006), we assessed the influence of enriched environment on the recovery process after perinatal hypoxic injury. Number and self-renewal of hippocampal GFAP + neural stem cells, as well as phenotype and long-term survival of the new neurons arising from these cells, were examined in both hypoxic and hypoxic enriched mice. Finally, we examined the functional outcome of hypoxic injury and 
subsequent enriched rearing on cognitive and emotive behavioral tasks.

We show that perinatal hypoxia enhances the proportion of new neurons arising from GFAP+ astroglial cells and correspondingly decreases the proportion of GFAP+ astrocytes among fate-mapped cells. The newly generated neurons persist long-term in the DG. Rearing the animals in enriched environment induces a large, additive increase in neurons derived from GFAP+ cell within the DG. We suggest that the effect of enrichment is attributable to a potent increase in proliferation and survival of neural stem cells.

\section{Materials and Methods}

Generation of mice, genotyping, and breeding strategy. The GCE mice were generated as previously described and back-crossed to C57/B6 mice 10 generations (Ganat et al., 2006; Bi et al., 2011). GCE transgenic mice carry a Cre recombinase-estrogen receptor type 2 fusion protein, CreErT2, placed under control of the human GFAP promoter, which is active in radial glia, astrocytes, and adult neural stem cells (Brenner, 1994; Ganat et al., 2006). Genotyping was done by PCR using primers to the Cre gene (5'-GCAACGAGTGATGAGGTTCGCAAG-3') (forward) and (5' TCCGCCGCATAACCAGTGAAACAG-3') (reverse) to generate a band of 307 bp (Ganat et al., 2006; Bi et al., 2011). GCE mice were crossed with either the R26R LacZ reporter mice (Soriano, 1999) (available from The Jackson Laboratory) or the CAG-eGFP reporter mice (where eGFP is enhanced green fluorescent protein) (Nakamura et al., 2006). Numbers of animals used in experiments ranged between three and six per group, as indicated in Results. Littermates negative for the CAG-eGFP gene were used for behavioral experiments. All animal experiments comply with institutional and national policies and guidelines.

Induction of Cre recombination via tamoxifen treatment. To induce Cre recombination in GFAP promoter-expressing cells, GCE mice crossed with reporter lines were injected daily from postnatal day 12 (P12) to P14 intraperitoneally with tamoxifen at a dosage of $60 \mathrm{mg} / \mathrm{kg}$ from a $2 \mathrm{mg} / \mathrm{ml}$ stock solution prepared in autoclaved sunflower seed oil and stored at $-20^{\circ} \mathrm{C}$.

Hypoxic rearing. Mice (males and females) were placed in a chamber maintaining a $9.5-10.5 \% \mathrm{O}_{2}$ concentration by displacement with $\mathrm{N}_{2}$ as described previously (Fagel et al., 2006). Hypoxia began at P3 for $8 \mathrm{~d}$ until P11. A separate group of control (normoxic) mice were matched for strain and age. Mice were sacrificed at P15, P16, P35, or P90. Mice were perfused transcardially with $20 \mathrm{ml}$ of PBS followed by $25 \mathrm{ml}$ of $4 \%$ paraformaldehyde (PFA). Brains were post-fixed overnight in $4 \%$ PFA, followed by equilibration in a $30 \%$ sucrose solution overnight for cryoprotection, and stored at $-80^{\circ} \mathrm{C}$.

Enriched environment. Following hypoxic or normoxic rearing conditions, male and female mice were placed under either enriched or standard housing until sacrifice. Enrichment was maintained for 2 weeks from P21 to P35 or for 10 weeks from P21 to P90. All groups were counterbalanced for previous hypoxic experience; therefore four groups of animals were generated: normoxic standard environment (NSE), normoxic enriched (NEn), hypoxic standard environment (HSE) and hypoxic enriched (HEn). Environmental enrichment consisted of a larger cage $(10 " \times 19$ " $\times 8$ " h), a running wheel, and several plastic toys, including hanging objects, balls, and modular plastic tunnels, that were changed and reconfigured weekly during routine cage cleaning. Animals were group housed in both the standard and enriched paradigms.

Behavioral testing. To assess the functional outcome of both hypoxia and enriched environment, GCE;CAG-negative littermates of mice used in the fate-mapping experiments were tested on the open field and Morris water maze tests at P35.

Mice were brought to the behavioral testing room in their home cages at least $30 \mathrm{~min}$ before testing to acclimatize them to the testing environment. Mice were then placed in an open field $(26 \times 48 \mathrm{~cm})$ under bright overhead lights and allowed to explore freely for $20 \mathrm{~min}$. Distance and time spent in the periphery and center of the open field as well as freezing bouts and immobility were all assessed using the AnyMaze software tracking system (Stoelting). Following this, mice were tested on a short-
Table 1. Primary antibodies

\begin{tabular}{|c|c|c|c|}
\hline Antibody & Manufacturer & Species & Dilution \\
\hline$\beta$-Galactosidase & Cappel & Rabbit & $1: 10,000$ \\
\hline$\beta$-Galactosidase & Abcam & Chicken & $1: 500$ \\
\hline BrdU/CldU & Accurate Chemical & Rat & $1: 250$ \\
\hline BrdU/IdU & Becton-Dickenson & Mouse & 1:100 \\
\hline Doublecortin & Abcam & Rabbit & $1: 2000$ \\
\hline Doublecortin & Santa Cruz & Goat & $1: 500$ \\
\hline GFAP & Sigma & Mouse & $1: 500$ \\
\hline GFAP & Dako & Rabbit & 1:1000 \\
\hline GFP & Molecular Probes & Rabbit & $1: 500$ \\
\hline GFP & Abcam & Chicken & 1:1000 \\
\hline Ki67 & Vector Laboratories & Rabbit & $1: 500$ \\
\hline Neuronal Nuclei & Chemicon & Mouse & $1: 500$ \\
\hline $\mathrm{Ng} 2$ & Millipore & Mouse & $1: 500$ \\
\hline Olig2 & $\begin{array}{l}\text { Kindly provided by Drs. Charles Stiles and John } \\
\text { Alberta, Dana-Farber Cancer Institute, Boston, } \\
\text { MA }\end{array}$ & Rabbit & $1: 20,000$ \\
\hline Sox2 & Chemicon & Goat & $1: 200$ \\
\hline $\mathrm{Ng} 2$ & Chemicon & Rabbit & $1: 500$ \\
\hline Sox2 & Chemicon & Goat & $1: 200$ \\
\hline
\end{tabular}

ened Morris water maze protocol adapted from J. Nunez, Michigan State University, East Lansing, MI (Nunez, 2008). Briefly, mice were placed in each of the four quadrants of the water maze in random order. The platform remained in a fixed location until the probe trial. Mice received two sets of six trials separated by a $1 \mathrm{~h}$ break. Each trial (intertrial interval was $10 \mathrm{~min}$ ) ended either when they found the platform or after $60 \mathrm{~s} \mathrm{had}$ elapsed. Mice that did not find the platform during the first trial were gently guided to the platform and removed from the platform after $5 \mathrm{~s}$. Ten minutes following the 12th trial, the platform was removed and memory retention for the platform location was tested with a $60 \mathrm{~s}$ probe trial. We assessed both the number of trials it took for $>50 \%$ of the animals in a group to find the platform (the rate of acquisition) and the quadrant preference during the probe trial (memory test-presented as both percentage of time spent in the target quadrant and a probe preference score).

2-Bromodeoxyuridine, chlorodeoxyuridine, and iododeoxyuridine treatment. To assess the effect of environmental enrichment on cell survival, normoxic mice were injected with the thymidine analog chlorodeoxyuridine (CldU) $(100 \mathrm{mg} / \mathrm{kg})$ twice on P15 and P16, before the onset of enrichment. Cell proliferation was assessed by injecting the thymidine analog iododeoxyuridine (IdU) $(100 \mathrm{mg} / \mathrm{kg}) 1 \mathrm{~h}$ before sacrifice at P35.

Tissue preparation and immunohistochemistry. Serial $20 \mu \mathrm{m}$ cryosections were obtained as described previously (Ganat et al., 2006). For immunohistochemistry, sections were blocked in PBS containing 0.3\% Triton (PBS-T) containing 10\% goat serum (10\% GS/PBS-T) or $10 \%$ donkey serum (10\% DS/PBS-T), and then incubated in primary antibody in $10 \%$ GS/PBS-T or DS/PBS-T. For a list of primary antibodies, see Table 1 . Sections were washed thoroughly and then reacted to the secondary antibody of the appropriate species. The secondary antibodies used were as follows: Alexa Fluor 488-, Alexa Fluor 594-, Alexa Fluor 350-, Alexa Fluor 546-, and Alexa Fluor 632-conjugated species directed IgGs (Invitrogen) and FITC-, DyLight 549- and DyLight 649-conjugated species directed IgGs (Jackson Laboratories), all at 1:500 dilution. For BrdU/CldU/IdU immunostaining, sections were incubated for $45 \mathrm{~min}$ in $2 \mathrm{~N} \mathrm{HCl}$, followed by washes and immunohistochemistry as described above.

Cell counting and microscopic analysis. Unbiased estimates of cell number were obtained via a Zeiss Axioskope 2 Mot Plus (Carl Zeiss) attached to a motorized stage and connected to a computer running the StereoInvestigator software (MicroBrightfield). Serial sagittal sections (one every $600 \mu \mathrm{m}$ ) were used for all counts. Contours of the dentate gyrus were drawn at $10 \times$ magnification. Nuclear profiles of stained cells were counted using the optical fractionator probe with a $40 \times$ oil immersion objective. Sampling grids sized $300 \times 135 \mu \mathrm{m}$ were used to obtain a relatively constant number of cells sampled and obtain a coefficient of 
error $\leq 0.5$. This systematic yet unbiased method provides an estimate of cell density and number that is independent from cell size, shape, orientation, tissue shrinkage, and spatial distribution of the cells (Schmitz and Hof, 2005). Tri-dimensional sampling boxes or $(100 \times 100 \times 10 \mu \mathrm{m})$ with three of six exclusion borders (Gundersen et al., 1988; West, 1993) were automatically placed by StereoInvestigator at each grid intersection point. The density for each cell type was calculated by dividing the total number of cells by the total volume sampled. Image acquisition and Z-stack analysis was performed on an ApoTome-equipped Axiovert 200M with Axiovision 4.5 software (Carl Zeiss).

Statistical analyses. All data were analyzed using Statview 4.51 or SPSS 16.0.2 software. T tests or factorial ANOVA were used as necessary, with level of enrichment (enriched or not) and/or hypoxia (hypoxic or normoxic) as independent variables. The density of cells/region, total overall number of cells, and, where appropriate, the percentage colocalization with $\beta$-galactosidase ( $\beta$ gal) or eGFP reporter were analyzed. $F$ values were considered significant when $p \leq 0.05$. Post hoc analyses using Fisher's least significant difference were conducted when $p$ values reached significance. Planned comparisons were conducted to confirm previously published results when omnibus $F$ scores were not significant.

\section{Results}

\section{Characterization of the original}

population of

reporter-tagged cells in the DG

To track the fate of GFAP + astroglial cells after hypoxic injury in the immature brain, we used a genetic fate-mapping technique that we have previously employed to characterize cerebral cortical re-

covery following hypoxic injury (Bi et al., 2011). GCE mice carrying either the R26R or the CAG-CAT-eGFP reporter genes were reared continuously in 10 or $20 \%$ oxygen environment (hypoxia and normoxic, respectively) from P3 to P11, then injected daily with tamoxifen $(60 \mathrm{mg} / \mathrm{kg})$ from P12 to P14 to induce either $\beta$ gal or eGFP gene expression in cells with GFAP promoter activity. Tissue was analyzed at P15 ( $n=4$ for both groups) (Ganat et al., 2006; Bi et al., 2011). Although we have previously observed no differences in reporter induction between normoxic and hypoxic groups using this model (Bi et al., 2011), these observations were primarily conducted in the cortex and subventricular zone; therefore, we confirmed that this was also true of the dentate gyrus. As expected, GCE;reporter + mice that did not receive tamoxifen demonstrated no recombination, regardless of the survival time after vehicle administration (Fig. $1 A, B$ ). One day after the last tamoxifen injection (P15), $95.7 \pm 3.1$ and $92.7 \pm$ $0.9 \%$ of the cells expressing the $\beta$ gal reporter also expressed GFAP protein in the DG in normoxic and hypoxic animals, respectively (Fig. 1C-E). At the same age, no reporter + cells were colabeled with mature markers for neurons (NeuN) or oligodendrocytes (RIP) in the hippocampus of either normoxic or hypoxic conditions (Fig. $1 \mathrm{~F}-\mathrm{H}$ and data not shown). These data are consistent with our previous examination of the cerebral cortex of GCE-CAG mice (Bi et al., 2011).
Hippocampal neurogenesis from fate-mapped astroglial lineage cells increases after hypoxic injury

To assess whether hypoxic rearing alters the fate of GFAP + cells, GCE;R26R and GCE;CAG-eGFP hypoxic and normoxic mice were injected with tamoxifen at P12-P14 and sacrificed at P35 ( $n=3$ for both groups).

Although the data only approached statistical significance, an increase in density of reporter $+\mathrm{Dcx}+$ neuronal progenitors and percentage Dcx + cells among reporter + cells was noted in the DG (Fig. $2 A-F)$ at P35; the percentage of $\beta$ gal + cells expressing Dcx in the DG increased from $56.4 \pm 2.9$ in normoxia to $68.3 \pm$ 1.7 in hypoxia $(p=0.058)$. To further examine the fates of GFAP + cells after hypoxia, we double stained reporter + cells at P35 with markers for mature neurons and glia. The number of reporter $+\mathrm{NeuN}+$ cells in the DG at P35 was twofold increased in hypoxic-reared mice, implying that the number of 3-week-old DG neurons born after the insult from GFAP+ precursors was significantly enhanced. The total number of fate-mapped new DG neurons was $1860 \pm 360$ and $3580 \pm 440$ in normoxic and hypoxic animals, respectively ( $p<0.05$; Student's $t$ test) (Fig. $2 G-L)$. The proportion of reporter + cells expressing NeuN also increased significantly after hypoxic rearing, from $55.7 \pm 0.5 \%$ in normoxia to $66.2 \pm 3.3 \%$ under hypoxia $(p<0.05$; Student's $t$ test), and concomitantly the proportion of reporter + cells ex- 

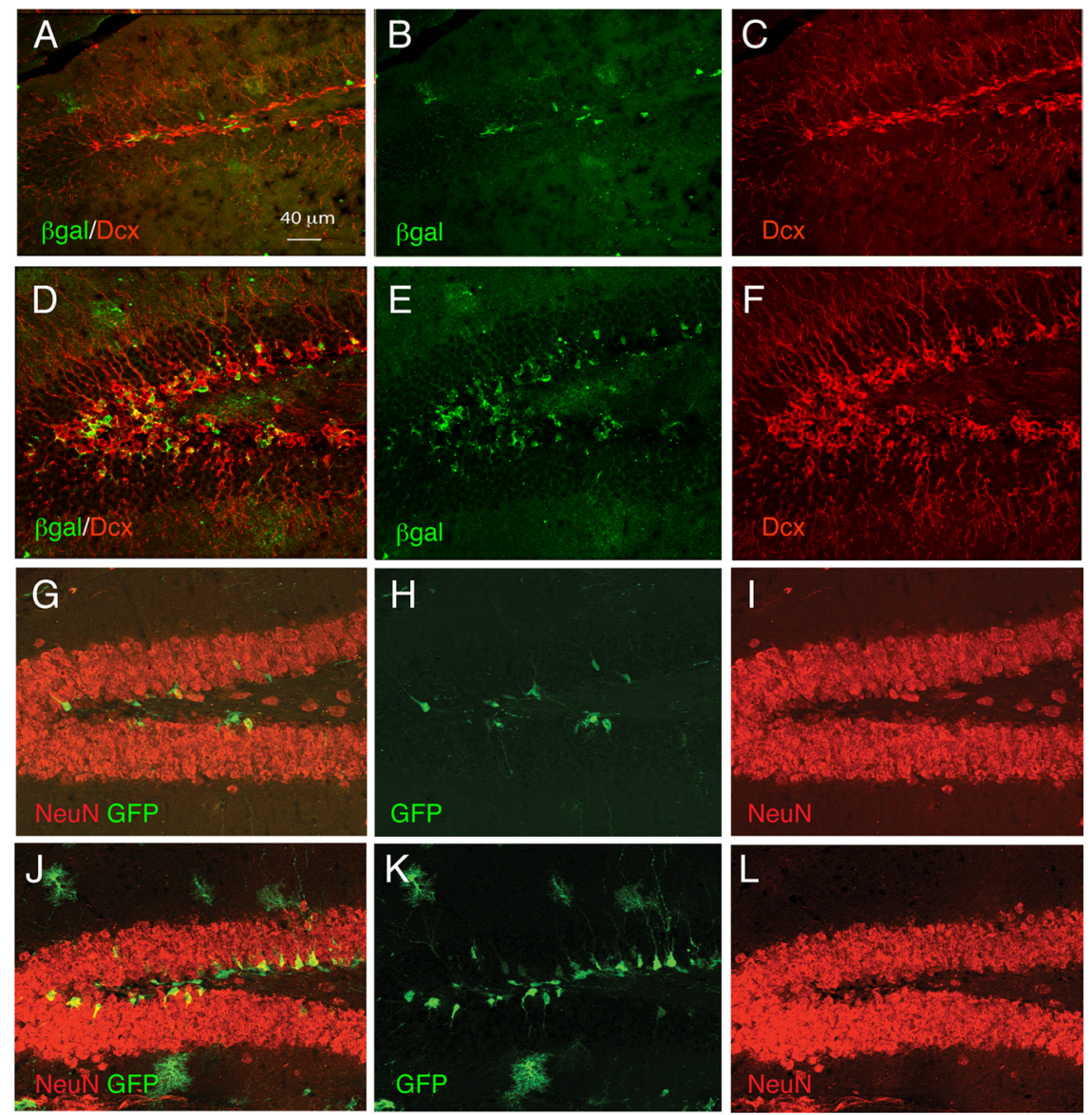

Figure 2. Increased neurogenesis from fate mapped astroglial lineage cells following hypoxia. GCE;R26R and GCE;eGFP mice were tamoxifen-injected at P12-P14 and analyzed at P35. Hypoxic reared mice had increased numbers of reporter $+/ D C X+$ immature neurons $(\boldsymbol{D}-\boldsymbol{F})$ and reporter $+/ \mathrm{NeuN}+$ mature neurons $(\boldsymbol{J}-\boldsymbol{L})$ in the dentate gyrus as compared to normoxic mice (A-C, G-I). Scale bar, $40 \mu \mathrm{m}$.

pressing GFAP decreased from $49.1 \pm 2.2$ to $35.1 \pm 4.8$. These data suggest that hypoxic rearing increases the proportion of fatemapped astroglial cells that differentiate toward a neuronal fate.

\section{Environmental enrichment increases neurogenesis from GFAP+ cells}

We next assessed both the ability of newly generated neurons to survive long term and the effect of environmental enrichment on their development. For these experiments, GCE mice carrying a reporter gene were reared under normoxic or hypoxic conditions until P11 and subsequently returned to standard environment or placed in enriched environment (En) upon weaning (P21) and then sacrificed at a juvenile/young adult stage (P35) or full adulthood (P90) (see Fig. $3 A$ for a schematic outline of the experiment). For each of the four groups (normoxic standard environment, NSE; normoxic enriched environment, NEn; hypoxic standard environment, HSE; hypoxic enriched environment, HEn) we used the following number of mice: P35, $\beta$ gal reporter: $n=4$ for all groups; eGFP reporter: NSE, $n=3$; NEn, $n=4$; HSE, $n=6$; Hen, $n=4$; P90, $n=3$ for all groups). We assessed the effect of enrichment on the number of newly generated neuronal cells arising from the GFAP lineage by analyzing Dcx and NeuN double staining of reporter + cells in the DG at P35. We found that hypoxia and environmental enrichment independently increased neurogenesis from GFAP + astroglial cells by about fourfold, and that in hypoxic enriched mice neurogenesis (both DCX + and NeuN + cells) from astroglial cells increased by $>6$-fold with respect to standard rearing (Fig. $3 B-I, N, O$ ). These changes were also reflected in the total number of eGFP + cells, where we observed a similar pattern of results (Fig. 3Q). In addition, hypoxic enriched mice showed a mild increase in the proportion of total granule neurons that expressed GFP from $2.2 \%$ in NSE to $3.1 \%$ in NEn, and from $3.4 \%$ in HSE to $5.6 \%$ in Hen mice at P35. Finally, a nearly additive pattern of hypoxia and enrichment on NeuN + cells was also observed at $\mathrm{P} 90$ (Fig. $3 J-M, P$ ).

To assess whether there were population fate shifts in response to hypoxia and environmental enrichment, we also examined the proportion of reporter + cells that coexpressed each of the lineage markers, NeuN, Olig2, and GFAP in the four groups at P35 and found an increase in the proportion of reporter + cells that expressed NeuN in both hypoxic and enriched mice. This increase in proportion of GFAP + NSCs attaining neuronal fate seemed to be at the expense of the astroglial population, as there was a concomitant decrease in the proportion of reporter+ cells expressing GFAP (Fig. $3 R)$. In contrast to our previous observations in the cortex (Bi et al., 2011), very few GFAP + cells attained an oligodendroglial fate in the DG; only one or two reporter + Olig2 + cells were observed in the DG per animal, and these were only seen in the enriched conditions.

\section{Effect of hypoxia and subsequent enrichment on NSCs}

Hypoxia and environmental enrichment increase neurogenesis from GFAP + astroglial cells in a nearly additive fashion. We wanted to understand whether this prolonged increase in neuronal production depletes the DG stem cell pool or whether this population was replenished and the number sustained. To assess this, we counted the number of reporter + cells that expressed Sox2, a transcription factor expressed by neural stem cells and, in a minor part, by neuronal progenitors (Avilion et al., 2003; Komitova and Eriksson, 2004; Episkopou, 2005). We found that at 2 weeks after the onset of enrichment (P35), there was a drastic increase in the total number of fate-mapped Sox $2+$ cells in both normoxic and hypoxic enriched groups (Fig. 4, compare $A-J$ with $K-T$, quantified in $U$ ). By contrast, the total number of fate mapped Sox $2+$ neural stem cell population did not significantly change due to hypoxia alone (Fig. 4, compare $A-E$ with $F-J$, quantified in $U$ ).

To understand whether there are fate shifts within the neural stem cell population, we also examined the proportion of eGFP+ cells that expressed neural stem cell and progenitor markers. We found a decrease in the proportion of eGFP + cells expressing Sox $2+$ in both hypoxic, standard environment-reared mice and in hypoxic enriched mice. The decrease in the proportion of eGFP+/Sox $2+$ cells was concomitant to an increase in the pro- 
A
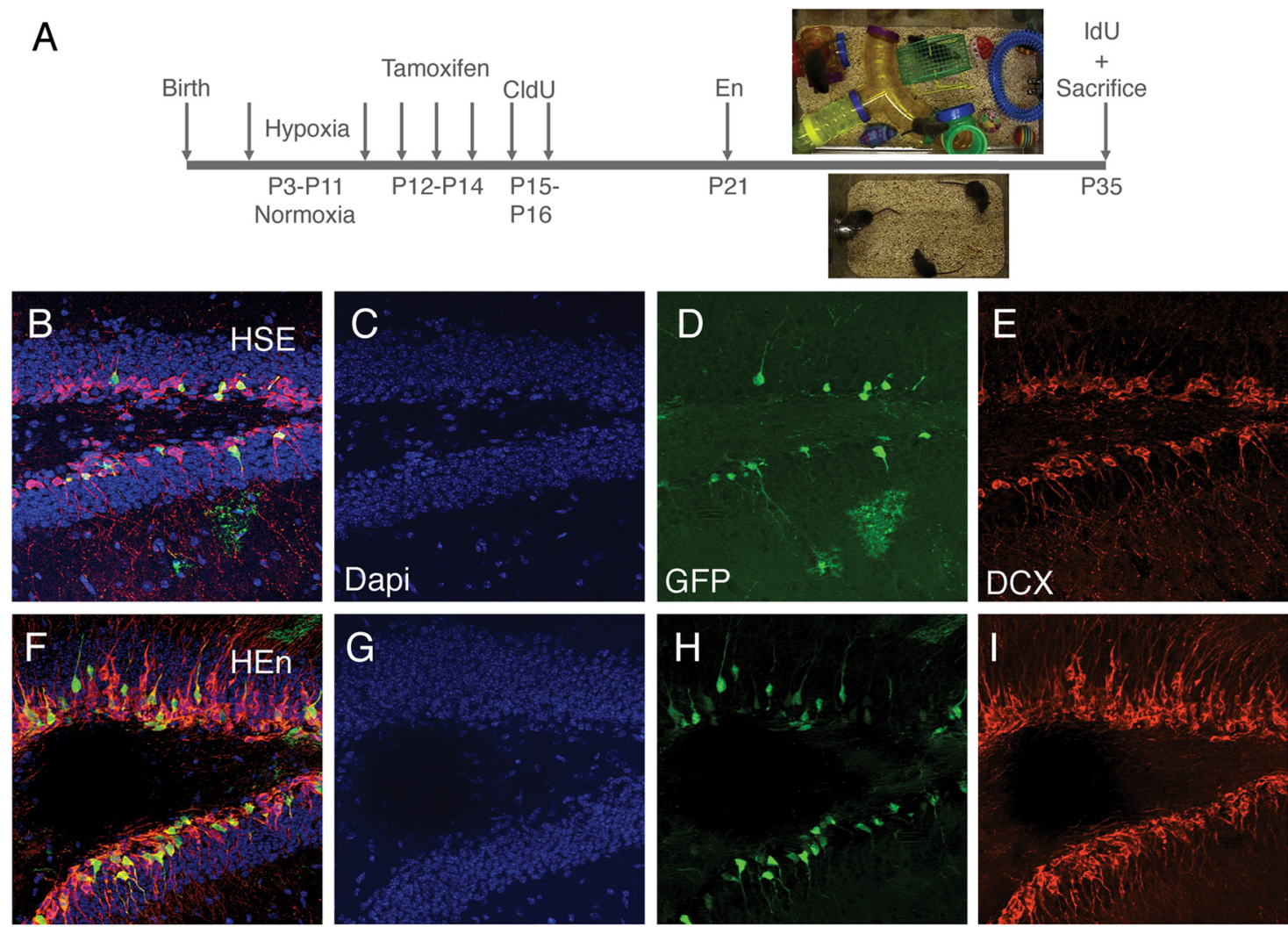

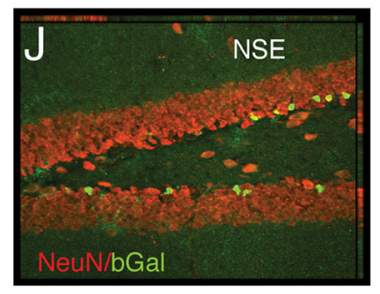

$\mathrm{N}$

Total \# of DCX+GFP+ cells at P35

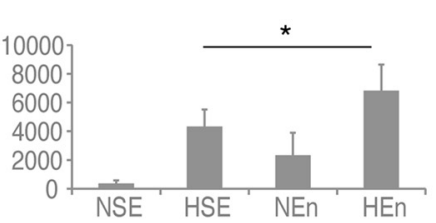

Q

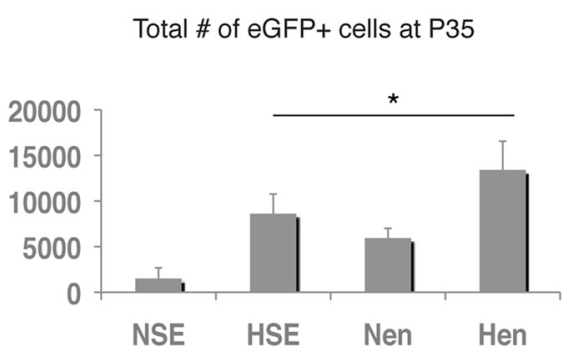

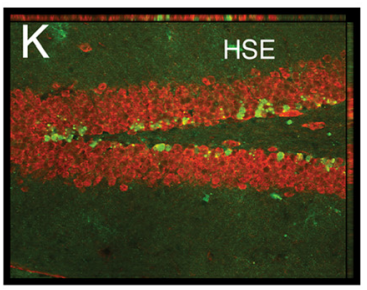

O

Total \# of NeuN+GFP+ cells at P35

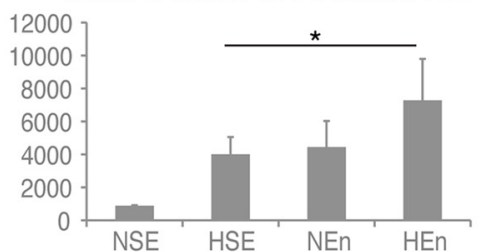

$\mathrm{R}$
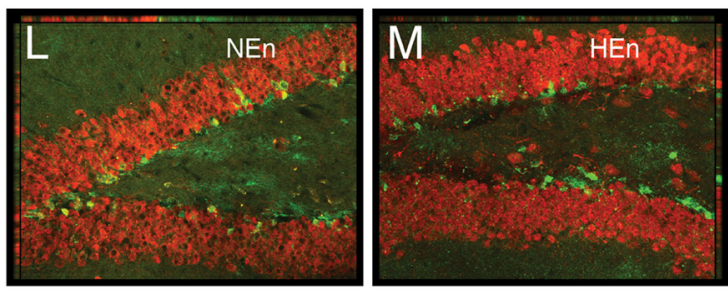

$\mathrm{P}$
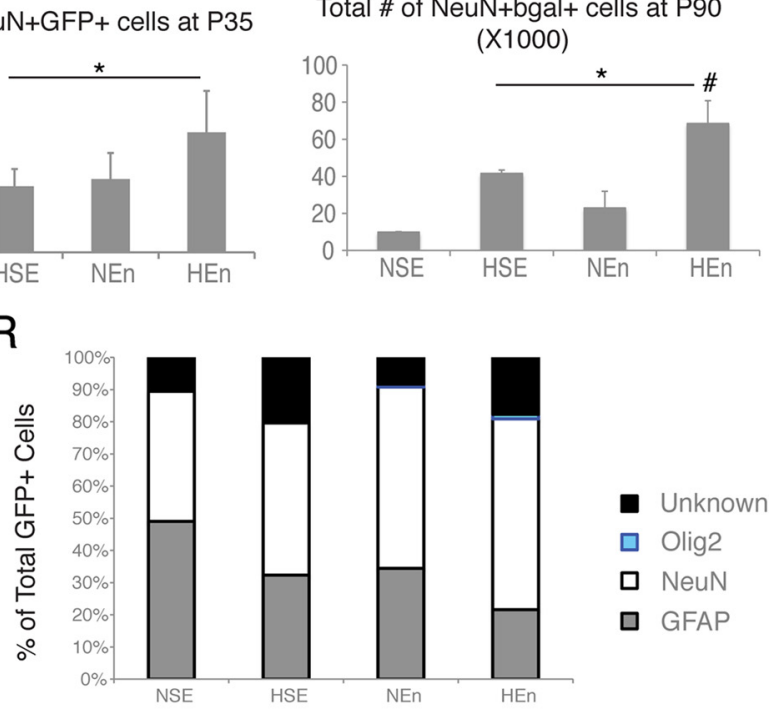

- Unknown

$\square$ Olig2

$\square$ NeuN

$\square$ GFAP

Figure 3. Hypoxia and subsequent environmental enrichment increase the number of neurons arising from GFAP + cells in an additive way. $\boldsymbol{A}$, Schematic of the time course of hypoxia and enrichment experiment. $\boldsymbol{B}-\boldsymbol{I}$, Representative images showing the increase in reporter $+/ D C X+$ neurons in hypoxic, enriched mice $(\boldsymbol{F}-\boldsymbol{I})$ as compared to hypoxic, standard reared mice $(\boldsymbol{B}-\boldsymbol{E})$ at $P 35$; stereological quantification of the reporter $+/ D C X+$ and reporter $+/ \mathrm{NeuN}+$ cell numbers is shown in $\boldsymbol{N}$ and $\mathbf{0}$, respectively. $\boldsymbol{J}-\boldsymbol{M}, \mathbf{L}$ Long-term increase in mature reporter $+/ \mathrm{NeuN}+$ neurons in response to hypoxia and enrichment at P90, with stereological quantification of reporter + $/ \mathrm{NeuN}+$ cell numbers at P90 shown in $\boldsymbol{P}$. $\mathbf{Q}$, The total number of eGFP+ cells at P35 increases in hypoxic and enriched mice. $\boldsymbol{R}$, Proportion of reporter + cells that attain neuronal (NeuN+), astroglial (GFAP +) and oligodendroglial (0lig2) fate are shown across groups. ${ }^{*}$ denote significant increases from NSE; \# denotes significant difference from all other groups. 

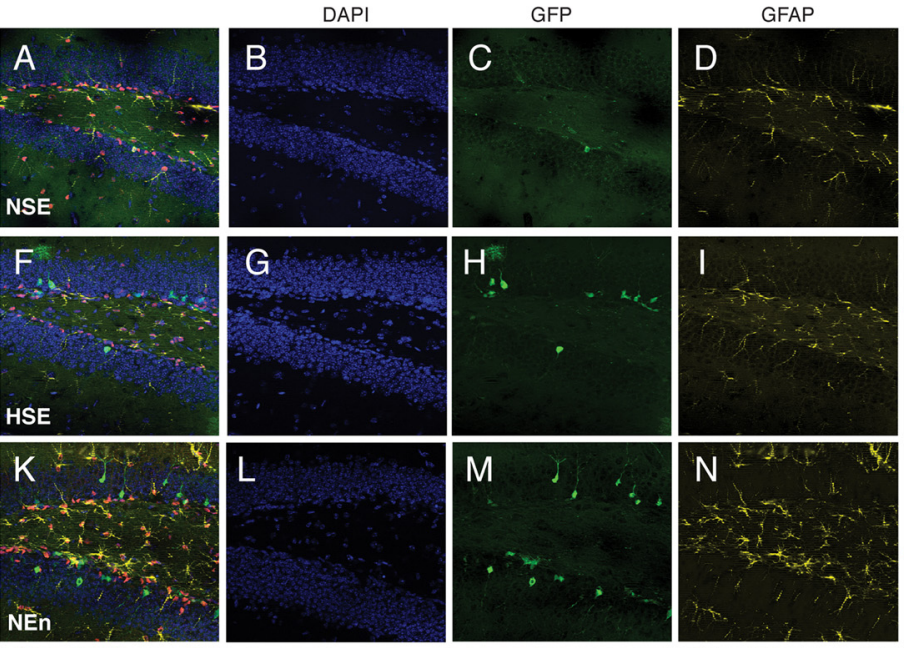

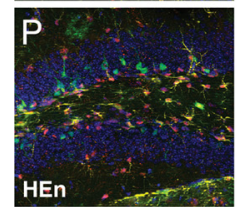

$\mathrm{U}$
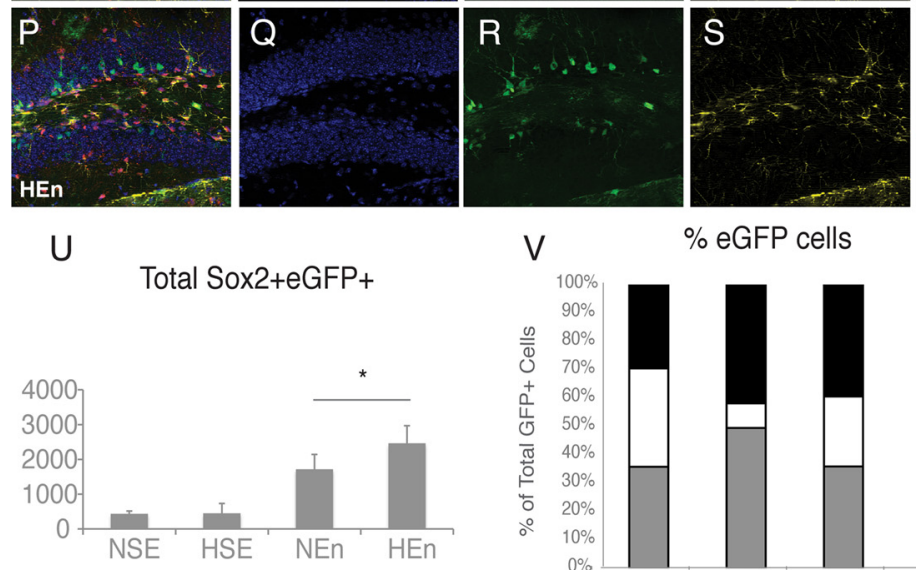

$\%$ eGFP cells

V

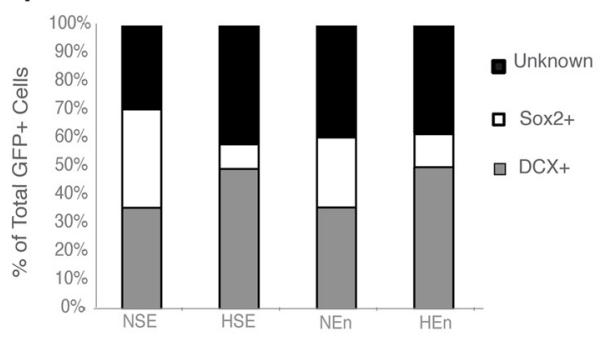

W Sox2+ colocalized w/DCX+

$X$
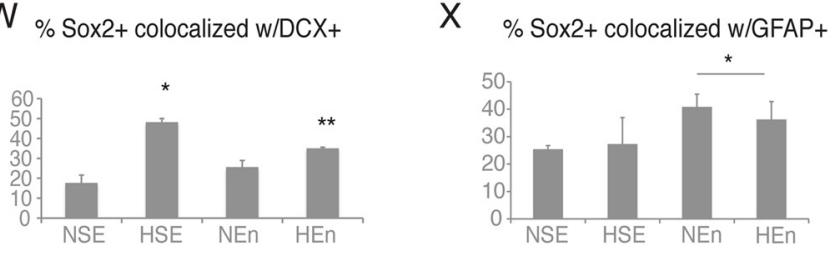

Y

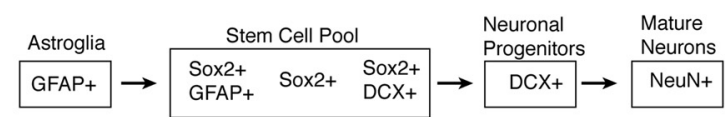

Figure 4. Hypoxia pushes stem cells to a neuronal fate, whereas enrichment increases the total stem cell pool. $\boldsymbol{A}-\boldsymbol{T}$, Representative Sox2/GFAP/eGFP immunostaining for all four groups; note the increase in number of Sox2 + cells expressing GFAP with environmental enrichment. $\boldsymbol{U}$, Environmental enrichment also increased the number of reporter $+/$ Sox $2+$ cells in both normoxic and hypoxic reared mice. $\boldsymbol{V}$, Proportion of reporter + cells that attain an immature neuronal $(D C X+)$ or stem cell $(S o x 2+)$ fate is shown across groups. $\boldsymbol{W}$, The percentage of Sox $2+$ stem cells that were committed to a neuronal lineage (colocalized with $D C X$ ) increased with hypoxic rearing, and this effect was attenuated with enrichment. $X$, The percentage of Sox2 + stem cells that remained in the NSC lineage (colocalized with GFAP) increased with enrichment. $Y$, Schematic representation of cell lineages arising from fate mapped GFAP + astroglia. ${ }^{*}$ denote significant increases from NSE; ${ }^{*}$ denotes significant increase from both NSE and HSE groups; - denotes significance from all other groups.

portion of eGFP cells expressing Dcx following hypoxia, with and without enrichment (Fig. $4 \mathrm{~V}$ ). In summary, hypoxia leads to an expansion of the DCX + neuroblast pool but has no effects on the number of Sox $2+$ cells.

To examine whether the shift in Sox + cells toward neuronal fate is also true of the total Sox $2+$ cell population (including both reporter + and reporter- cells), we counted the proportion of total Sox $2+$ cells that were colabeled with GFAP or Dcx (Fig. $4 W, X$, and scheme in $Y$ ). We found that the percentage of Sox $2+$
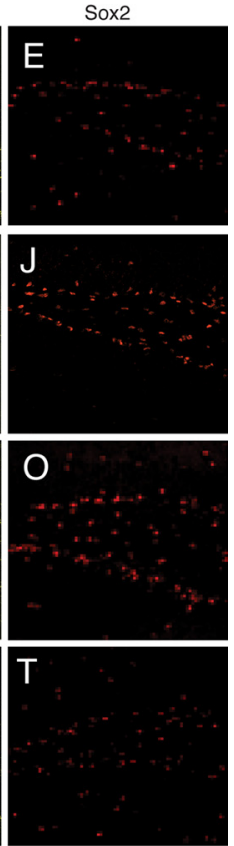

cells that were also Dcx + increased significantly in hypoxic, standard environmentreared mice, as well as in hypoxic enriched mice, although post hoc analysis showed that this last group remained significantly lower than the hypoxic, standard reared mice (Fig. $4 W$ ). In addition, enrichment increased the proportion of Sox $2+$ cells that were colabeled with GFAP, suggesting an increase in the stem cell pool (Fig. $4 X$ ). Together, it would seem that hypoxia induces a shift of stem cells toward a neurogenic fate that is not specific to the fatemapped population.

\section{Mechanisms of increased stem cell number in environmental enrichment} The increased neural stem cell number observed in response to environmental enrichment in the current study could be attained through increases in stem cell proliferation, stem cell survival, or a combination of both. To understand whether the increase in the stem cell pool in response to enrichment was due to changes in stem cell proliferation, we assessed the total number and proportion of Sox $2+$ cells that coexpress Ki67, a marker of cell proliferation at P35. As compared to animals reared in standard conditions, both enriched groups exhibited almost four times the total number of Sox $2+\mathrm{Ki} 67+$ cells (Fig. 5A-G), as well as a significant increase in the proportion of proliferating stem cells (Fig. $5 H$ ).

To further understand whether increased stem cell proliferation and survival contributed to our observations, we injected normoxic mice with two thymidine analogues, CldU given at P15 and $\mathrm{P} 16$ and IdU given $1 \mathrm{~h}$ before sacrifice. CldU, when incorporated in cells during their last mitotic division, allows us to examine the long-term survival of cells labeled before enrichment, and IdU, injected $1 \mathrm{~h}$ before sacrifice at P35, was given to examine cell proliferation (NSE, $n=4$; NEn, $n=3$ ). Coexpression of both of these markers in Sox $2+$ cells (Sox $2+$ CldU + and Sox $2+\mathrm{IdU}+)$ was increased $\sim 3$-fold in enriched mice at P35, two weeks after the onset of enrichment (Fig. 6). This suggests that both stem cell survival and cell proliferation contribute to the increased neurogenesis observed in response to environmental enrichment and that enhanced neurogenesis did not deplete the Sox $2+$ progenitor pool.

\section{Behavioral testing}

The four groups were tested for spatial memory using the Morris water maze task (NSE, $n=9$; NEn, $n=10$; HSE, $n=6$; HEn, $n=$ 9). Results showed that the rate of acquisition of new spatial information on the Morris water maze was significantly slower 
for the hypoxic, standard-reared mice; $50 \%$ of the mice were successful in reaching the platform within $60 \mathrm{~s}$ only by the seventh trial, whereas $50 \%$ of normoxic, standard-reared mice were successful by the end of the fourth trial. Interestingly, when hypoxic mice were reared in an enriched environment, they were no different from normoxic, standard-reared mice. The normoxic-enriched group reached criterion the fastest, by the second trial (Fig. 7A). During the probe trial for memory retention, hypoxic, standardreared mice showed a decreased preference for the target quadrant, indicating decreased recall for the platform location, whereas those hypoxic mice reared in an enriched environment were no different from both normoxic groups (Fig. $7 B, C)$.

In addition to cognitive deficits, VLBW children have also been shown to have an increased risk for anxiety disorders throughout the lifespan (Johnson et al., 2010; Lund et al., 2011). To assess whether our model of perinatal hypoxia also results in increased anxiety behavior, we assessed mice in the open field task at P35. We found that mice exposed to hypoxic conditions showed increased anxiety-like behavior, spending less time and traveling less distance in the center of the open field, regardless of whether mice were environmentally enriched subsequent to hypoxic injury (Fig. $7 D, E$ ). Taken together, these data demonstrate that hypoxic rearing results in cognitive and emotional deficits and that although the memory deficits can be reversed through as little as 2 weeks of environmental enrichment following hypoxic injury, anxiety behavior remains elevated regardless of enrichment status.

\section{Discussion}

The current studies used assays for cell proliferation, BrdU birthdating studies, and genetic fate mapping techniques to examine the fate of hippocampal GFAP+ astroglial cells after perinatal hypoxic insult and subsequent rearing in standard or enriched environment. We show that $\mathrm{GFAP}+$ cells in the juvenile period (P12-P15) generate astrocytes and neurons in the hippocampal DG, consistent with previous data indicating that hippocampal NSCs express GFAP. Chronic perinatal hypoxia shifts the long-term differentiation of juvenile GFAP + cells from an astrocytic to a neuronal fate. Rearing juvenile animals in an enriched environment, regardless of previous hypoxic experience, induced a long-lasting sixfold increase in the total number of hippocampal neurons generated from astroglial cells in the DG that persisted until adulthood. We have found that this effect of enrichment could be attributed to
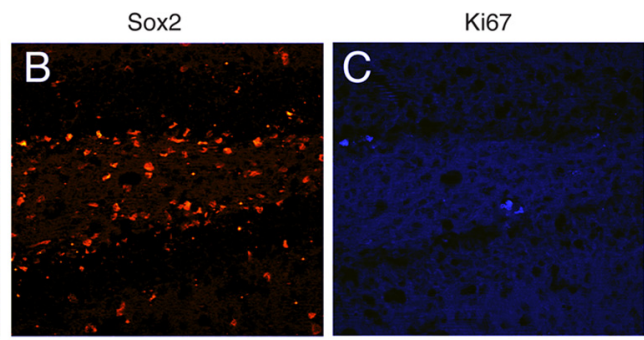

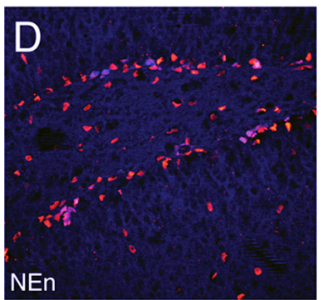

G

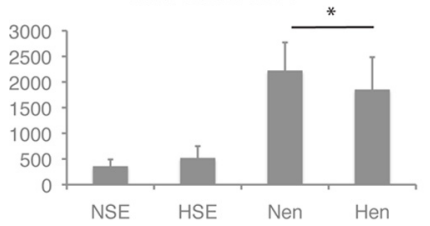

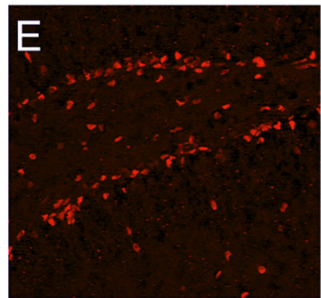

$\mathrm{H}$

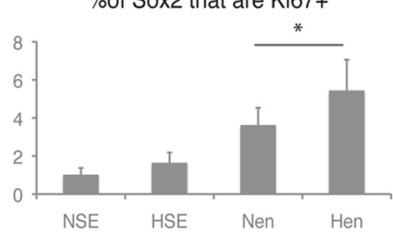

Figure 5. Effect of hypoxia and environmental enrichment on stem cell proliferation. GCE;R26R mice reared under normoxic or hypoxic conditions followed by environmental enrichment as indicated were analyzed at P35. $\boldsymbol{A}-\boldsymbol{H}$, Representative double staining of Sox2 and Ki67 at P35. Stereological quantification showed an increase in the total number $(\boldsymbol{G})$ and proportion $(\boldsymbol{H})$ of proliferating Sox2 + cells in response to environmental enrichment. No increase in stem cell proliferation was observed in response to hypoxic rearing $(\boldsymbol{G}-\boldsymbol{H})$. ${ }^{*}$ denote significance from all other groups.
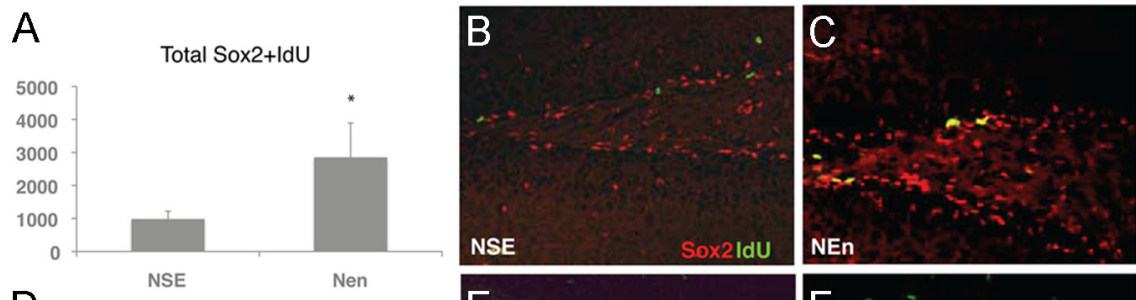

Figure 6. Environmental enrichment increases stem cell proliferation and survival. GCE;R26R and GCE;eGFP normoxic-reared mice were tamoxifen injected from P12-14, subsequently injected with CldU from P15-16 (to examine cell survival) (see schematic outline in Fig. 4 A), reared in enriched or standard environment from P21-P35, and then injected with IdU $1 \mathrm{~h}$ before sacrifice (to examine cell proliferation) at P35. Both Sox2 + cell proliferation $(\boldsymbol{A}-\boldsymbol{C})$ and Sox2 + cell survival $(\boldsymbol{D}-\boldsymbol{F})$ were significantly increased in enriched mice. ${ }^{*}$ denote significant increases from NSE.

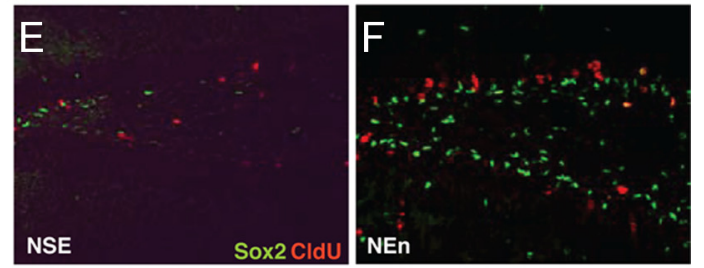

an increase in the stem cell pool due to increased NSC proliferation and survival.

The mouse model of perinatal hypoxia that we employ is unique in that it is probably the best model for brain injury in VLBW premature children (Vaccarino and Ment, 2004; Scafidi et al., 2009), which are now $\sim 1.5 \%$ of all children born in the USA (Ment and Constable, 2007; Luu et al., 2009). Unlike models of neonatal stroke, chronic hypoxic injury is a more generalized insult; it does not seem to induce local acute effects such as reactive gliosis or focal leukomalacia, although it does have abnor- 


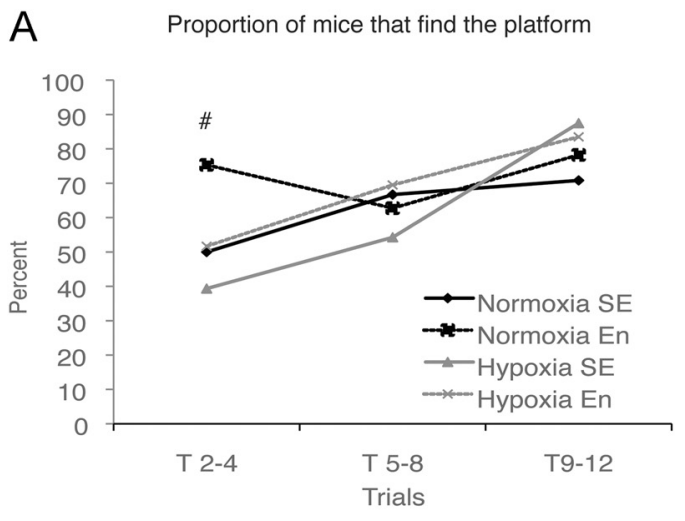

B Mean Latency to find platform (s)

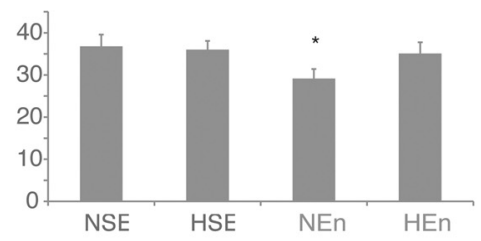

C Time in target quadrant during

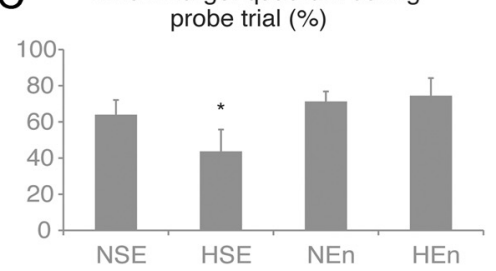

D

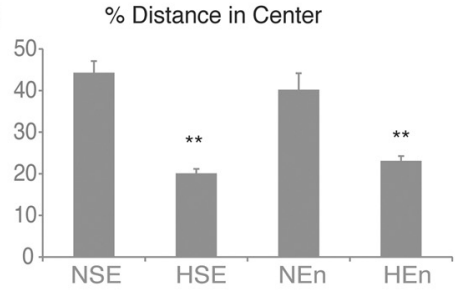

E

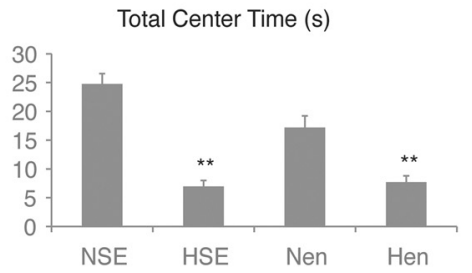

Figure 7. Environmental enrichment reverses hypoxia-induced cognitive deficits. Mice were reared in normoxia or hypoxia from P3 to P11 and subsequently in standard or enriched environment from P21 to P35. Behavioral testing was conducted on P35-36. $\boldsymbol{A}-\boldsymbol{C}$, Results of the Morris water maze. $\boldsymbol{A}$, The proportion of mice that successfully found the platform in under $60 \mathrm{~s}$, averaged across six trials, during the acquisition phase on the maze. $\boldsymbol{B}$, The latency to find the platform across trials. $\boldsymbol{C}$, Probe trial. $\boldsymbol{D}, \boldsymbol{E}$, Results from the open field test. $\boldsymbol{D}$, Proportion of distance traveled in the center/total distance traveled. $\boldsymbol{E}$, Time spent in the center. ${ }^{*}$, Significance from all other groups; ${ }^{*}$, significance from NSE and NEn groups, \#, HSE and NEn are different from all other groups.

malities in white matter development, including delayed maturation of oligodendrocytes and abnormal myelination (B. Jablonska, J. Scafildi, A. Aguirre, F. Vaccarino, E. Borok, T. Horvath, V. Gallo, unpublished observation). Interestingly, among the best predictors of positive outcome in VLBW children are a two-parent household and an increased level of maternal educa-

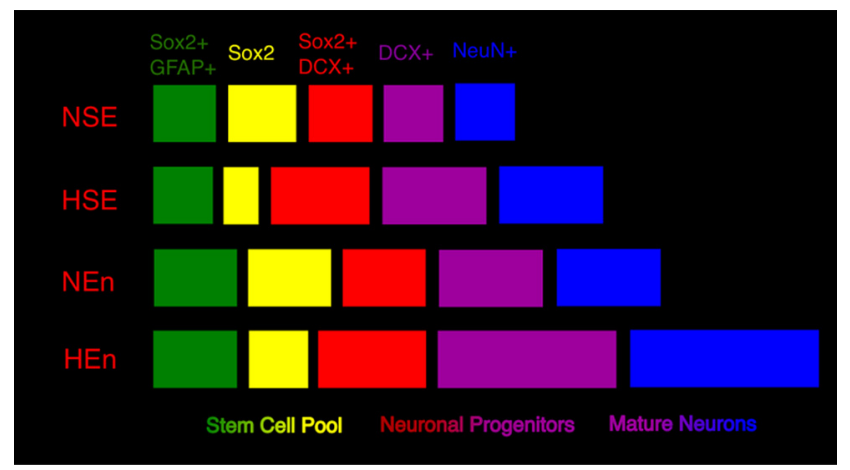

Figure 8. Schematic representation depicting hypoxia- and enrichment-induced changes in astroglial lineage. There is an increase in the number of neuronal cells in hypoxic-reared as well as normoxic enriched mice, shown in purple $(\mathrm{DCX}+)$ and blue $(\mathrm{NeuN}+)$. HEn mice show the greatest increase in total number of reporter + neurons, suggesting an additive effect of hypoxia and enrichment on neurogenesis arising from GFAP + cells. HSE mice show a greater proportion of the stem cell pool that is committed to the neuronal lineage (Sox2+DCX+, shown in red); this effect remains apparent in hypoxic mice that were subsequently enriched. In NEn mice there is no change in fate potential of NSC but rather a robust increase in the total stem/progenitor cell pool (shown in green, yellow, red) that is still present in Hen mice.

tion (Ment et al., 2003). This raises the important question of the mechanisms by which increased environmental stimulation of VLBW children months and years after the perinatal insult improves recovery (Ment et al., 2003). It has been well documented in adult rodents that environmental enrichment not only increases cell proliferation and neurogenesis, but increases the ability of new neurons to differentiate, integrate, and mature in the DG (Kempermann et al., 2004). However, the cognitive and neurobiological effect of environmental enrichment during development and, in particular, its ability to interact with prior hypoxic injury has not been investigated. Our fate mapping studies show that environmental enrichment for 2 weeks increased the number of neurons generated from astroglial cells in the DG at P35 but did not augment the neurogenic effect of hypoxia. Interestingly, extending the enrichment until full adulthood (P90) increased neurogenesis in both normoxic and hypoxic mice, and the effects of hypoxia and enrichment appeared independent and additive. It is likely that the increase in total number of fate-mapped neurons described here is a gross underestimation of the neurogenesis that occurs in response to hypoxia and environmental enrichment. The population of fatemapped neurons that we observe arise from GFAP + cells labeled from P12-P14 only; furthermore, the targeting efficiency of the GCE transgene is not $100 \%$ (Ganat et al., 2006). Therefore, these neurons likely represent a small fraction of the total neurogenesis induced by hypoxia and enrichment in these mice. Indeed, at P35, we show that the proportion of fate-mapped neurons relative to the total number of granule neurons ranges across groups from $\sim 2$ to $6 \%$, whereas a recent study by Cushman et al. (2012) demonstrates that the proportion of total DG neurons born from GFAP + cells was $24 \%$ at 2 months of age, suggesting that we are capturing about one-fourth of the total number of neurons arising from GFAP+ precursors (Cushman et al., 2012).

Increased neurogenesis can be attributed to a shift in fate of the GFAP + stem cells toward the neuronal lineage or to a change in progenitor proliferation or neuronal survival. Moreover, increased neurogenesis will, over the long term, deplete the astroglial stem cell population unless these cells self-renew via asymmetric division. We find that hypoxia induced a fate shift in 
juvenile GFAP+ cells away from the astroglial lineage and in favor of the doublecortin (DCX) neuronal lineage (Fig. 4V). Although a similar increase in total number of DCX $+/ \mathrm{NeuN}+$ cells was seen in response to environmental enrichment, no fate shift toward the DCX lineage was observed in normoxic enriched animals. Our results show that environmental enrichment causes a robust increase in size of the astroglial stem cell population that is attributable to enhanced NSC self-renewal as well as survival, as shown by the Ki67 double labeling and CldU/IdU incorporation experiments. Hypoxic-rearing on its own does not increase the stem cell pool and, in fact, hypoxia increases the proportion of GFAP+ and Sox $2+$ stem cells that coexpress the neuronal progenitor marker DCX (Fig. $4 \mathrm{~V}, \mathrm{~W}$ ), suggesting that more of these cells are committing to a neuronal fate. Subsequent exposure of hypoxic-reared animals to environmental enrichment increased the proportion of Sox $2+$ cells coexpressing GFAP (Fig. $4 X$ ) as well as the total number of stem cells (Fig. $4 U$ ), suggesting that both a fate shift toward the neuronal lineage and an increase in the number of stem cells may be acting together in hypoxic enriched mice, accounting for the additive effect on the number of newly generated neurons.

Together, our results suggest that hypoxia alone increases neurogenesis by pushing the stem cell population toward a neuronal fate, whereas enrichment increases the total stem cell population. Consequently, hypoxia coupled with enrichment enables neurogenesis from GFAP + astroglia to rise without depleting the population of Sox $2+$ neural stem cells and maintaining their proportion relative to neuroblasts (Fig. 8). Thus, the robust longterm increase in neurogenesis that we have observed in hypoxic enriched mice can be attributed to the hypoxia-induced neurogenic shift coupled with an overall increase in the stem cell pool observed in response to environmental enrichment. Interestingly, the increase in stem cells we have observed in response to enriched environment may be unique to the early phase of enrichment. In a recent study, Hen and colleagues (Dranovsky et al., 2011) employed a similar genetic fate-mapping model driven by a Nestin-Cre promoter and demonstrated that exposing mice to long-term environmental enrichment in adulthood leads to a similar decrease in GFAP+/reporter + cells while increasing $\mathrm{NeuN}+$ /reporter + cells; however, unlike our current study, they did not observe a significant increase in the total number of reporter + stem cells in response to environmental enrichment (Dranovsky et al., 2011). The differential response of stem cells to enrichment observed between these studies may reflect differences in the age at which environmental enrichment was commenced (P21 in our study versus adult); however, it is also possible that it is a transient effect in response to the early phase of enrichment and, perhaps, to physical exercise with the running wheel (van Praag et al., 1999b; Kobilo et al., 2011). Indeed, a recent study examining the fate of hippocampal Hes5 + cells in adult mice that were given free access to a running wheel for $12 \mathrm{~d}$ showed increased proliferation of reporter + stem cells in mice with running wheel access as compared to controls (Lugert et al., 2010). Taken together, it seems more likely that at least in the hippocampus, the number of stem cells increase during the early phases of environmental enrichment; however, more detailed future studies examining the relative contribution of hippocampal GFAP + stem cells in response to environmental enrichment while controlling for age of onset, duration, and access to physical activity are needed to answer these questions.

The relative contribution of increasing the number of stem cells versus neurons to cognitive amelioration in hypoxic enriched mice remains to be determined. In the current study, hy- poxic mice show a similar increase in neurogenesis as do normoxic, enriched mice, yet hypoxic mice show a slower rate of acquisition and impaired retention, suggesting that hippocampal neurogenesis alone cannot account for the differences seen in cognitive performance. These findings are in support of previous work showing that the role of neurogenesis in learning and memory, as revealed by the Morris water maze task, is not clearly defined, with some studies finding a significant relationship and others not (Shors et al., 2002). Furthermore, it is also likely that behavioral changes in response to both hypoxia and environmental enrichment within other brain regions, such as white matter, cortex or the subventricular zone may contribute to our behavioral findings (Bi et al., 2011).

On the other hand, the increased performance seen in both enriched groups could be related to the increased stem cell pool also observed in these groups; albeit whether this is causally related remains to be determined. Although the current paper has focused on the hippocampus and GFAP + cell fate, environmental enrichment impacts other mechanisms of neural plasticity in the hippocampus that could also play a causal role in enhanced learning and memory, including synaptogenesis, inhibitory tone, and dendritic spine formation (Johansson and Belichenko, 2002; Sale et al., 2007; Bednarek and Caroni, 2011).

Longitudinal studies of VLBW children have shown that these children are more likely to be diagnosed with an anxiety disorder, even decades later (Johnson et al., 2010; Lund et al., 2011). Results from the open field test also showed increased anxiety in our mouse model. Interestingly, these effects were not ameliorated with short-term environmental enrichment, suggesting that anxiety behavior after hypoxic injury is mediated by different neurobiological changes that are not responsive to short-term enrichment.

In conclusion, we demonstrate that subsequent environmental enrichment after hypoxic injury reverses the cognitive deficits consequential to hypoxic injury. Furthermore, hypoxic injury and environmental enrichment together increase neurogenesis in the dentate gyrus in an additive, long-term manner. Environmental enrichment increases the total stem cell population through proliferation and survival, which ultimately leads to sustained increases in neurogenesis in hypoxic, enriched mice.

\section{References}

Alvarez-Buylla A, Seri B, Doetsch F (2002) Identification of neural stem cells in the adult vertebrate brain. Brain Res Bull 57:751-758.

Avilion AA, Nicolis SK, Pevny LH, Perez L, Vivian N, Lovell-Badge R (2003) Multipotent cell lineages in early mouse development depend on SOX2 function. Genes Dev 17:126-140.

Bednarek E, Caroni P (2011) $\beta$-Adducin is required for stable assembly of new synapses and improved memory upon environmental enrichment. Neuron 69:1132-1146.

Belachew S, Chittajallu R, Aguirre AA, Yuan X, Kirby M, Anderson S, Gallo V (2003) Postnatal NG2 proteoglycan-expressing progenitor cells are intrinsically multipotent and generate functional neurons. J Cell Biol 161:169-186.

Bi B, Salmaso N, Komitova M, Simonini MV, Silbereis J, Cheng E, Kim J, Luft S, Ment LR, Horvath TL, Schwartz ML, Vaccarino FM (2011) Cortical glial fibrillary acidic protein-positive cells generate neurons after perinatal hypoxic injury. J Neurosci 31:9205-9221.

Brenner M (1994) Structure and transcriptional regulation of the GFAP gene. Brain Pathol 4:245-257.

Brill MS, Snapyan M, Wohlfrom H, Ninkovic J, Jawerka M, Mastick GS, Ashery-Padan R, Saghatelyan A, Berninger B, Götz M (2008) A dlx2and pax6-dependent transcriptional code for periglomerular neuron specification in the adult olfactory bulb. J Neurosci 28:6439-6452.

Cushman JD, Maldonado J, Kwon EE, Garcia AD, Fan G, Imura T, Sofroniew MV, Fanselow MS (2012) Juvenile neurogenesis makes essential contri- 
butions to adult brain structure and plays a sex-dependent role in fear memories. Front Behav Neurosci 6:3.

Doetsch F, Caillé I, Lim DA, García-Verdugo JM, Alvarez-Buylla A (1999) Subventricular zone astrocytes are neural stem cells in the adult mammalian brain. Cell 97:703-716.

Dranovsky A, Picchini AM, Moadel T, Sisti AC, Yamada A, Kimura S, Leonardo ED, Hen R (2011) Experience dictates stem cell fate in the adult hippocampus. Neuron 70:908-923.

Episkopou V (2005) SOX2 functions in adult neural stem cells. Trends Neurosci 28:219-221.

Fagel DM, Ganat Y, Silbereis J, Ebbitt T, Stewart W, Zhang H, Ment LR, Vaccarino FM (2006) Cortical neurogenesis enhanced by chronic perinatal hypoxia. Exp Neurol 199:77-91.

Filippov V, Kronenberg G, Pivneva T, Reuter K, Steiner B, Wang LP, Yamaguchi M, Kettenmann H, Kempermann G (2003) Subpopulation of nestin-expressing progenitor cells in the adult murine hippocampus shows electrophysiological and morphological characteristics of astrocytes. Mol Cell Neurosci 23:373-382.

Ganat YM, Silbereis J, Cave C, Ngu H, Anderson GM, Ohkubo Y, Ment LR, Vaccarino FM (2006) Early postnatal astroglial cells produce multilineage precursors and neural stem cells in vivo. J Neurosci 26:8609-8621.

Garcia AD, Doan NB, Imura T, Bush TG, Sofroniew MV (2004) GFAPexpressing progenitors are the principal source of constitutive neurogenesis in adult mouse forebrain. Nat Neurosci 7:1233-1241.

Gundersen HJ, Bagger P, Bendtsen TF, Evans SM, Korbo L, Marcussen N, Møller A, Nielsen K, Nyengaard JR, Pakkenberg B (1988) The new stereological tools: disector, fractionator, nucleator, and point sampled intercepts and their use in pathological research and diagnosis. APMIS 96:857-881.

Hack MA, Saghatelyan A, de Chevigny A, Pfeifer A, Ashery-Padan R, Lledo PM, Götz M (2005) Neuronal fate determinants of adult olfactory bulb neurogenesis. Nat Neurosci 8:865-872.

Hevner RF, Hodge RD, Daza RA, Englund C (2006) Transcription factors in glutamatergic neurogenesis: conserved programs in neocortex, cerebellum, and adult hippocampus. Neurosci Res 55:223-233.

Imura T, Kornblum HI, Sofroniew MV (2003) The predominant neural stem cell isolated from postnatal and adult forebrain but not early embryonic forebrain expresses GFAP. J Neurosci 23:2824-2832.

Johansson BB, Belichenko PV (2002) Neuronal plasticity and dendritic spines: effect of environmental enrichment on intact and postischemic rat brain. J Cereb Blood Flow Metab 22:89-96.

Johnson S, Hollis C, Kochhar P, Hennessy E, Wolke D, Marlow N (2010) Psychiatric disorders in extremely preterm children: longitudinal finding at age 11 years in the EPICure study. J Am Acad Child Adolesc Psychiatry 49:453-463.e1.

Kempermann G, Kuhn HG, Gage FH (1997) More hippocampal neurons in adult mice living in an enriched environment. Nature 386:493-495.

Kempermann G, Wiskott L, Gage FH (2004) Functional significance of adult neurogenesis. Curr Opin Neurobiol 14:186-191.

Kernie SG, Parent JM (2010) Forebrain neurogenesis after focal Ischemic and traumatic brain injury. Neurobiol Dis 37:267-274.

Kobilo T, Liu QR, Gandhi K, Mughal M, Shaham Y, van Praag H (2011) Running is the neurogenic and neurotrophic stimulus in environmental enrichment. Learn Mem 18:605-609.

Komitova M, Eriksson PS (2004) Sox-2 is expressed by neural progenitors and astroglia in the adult rat brain. Neurosci Lett 369:24-27.

Kuhn HG, Palmer TD, Fuchs E (2001) Adult neurogenesis: a compensatory mechanism for neuronal damage. Eur Arch Psychiatry Clin Neurosci 251:152-158.

Lugert S, Basak O, Knuckles P, Haussler U, Fabel K, Götz M, Haas CA, Kempermann G, Taylor V, Giachino C (2010) Quiescent and active hippocampal neural stem cells with distinct morphologies respond selectively to physiological and pathological stimuli and aging. Cell Stem Cell 6:445-456.

Lund LK, Vik T, Skranes J, Brubakk AM, Indredavik MS (2011) Psychiatric morbidity in two low birth weight groups assessed by diagnostic interview in young adulthood. Acta Paediatr 100:598-604.

Luu TM, Ment LR, Schneider KC, Katz KH, Allan WC, Vohr BR (2009) Lasting effects of preterm birth and neonatal brain hemorrhage at 12 years of age. Pediatrics 123:1037-1044.

Luu TM, Vohr BR, Allan W, Schneider KC, Ment LR (2011) Evidence for catch-up in cognition and receptive vocabulary among adolescents born very preterm. Pediatrics 128:313-322.

Ment LR, Constable RT (2007) Injury and recovery in the developing brain: evidence from functional MRI studies of prematurely born children. Nat Clin Pract Neurol 3:558-571.

Ment LR, Vohr B, Allan W, Katz KH, Schneider KC, Westerveld M, Duncan CC, Makuch RW (2003) Change in cognitive function over time in very low-birth-weight infants. JAMA 289:705-711.

Nakamura T, Colbert MC, Robbins J (2006) Neural crest cells retain multipotential characteristics in the developing valves and label the cardiac conduction system. Circ Res 98:1547-1554.

Nunez J (2008) Morris water maze experiment. J Vis Exp pii: 897.doi: 10.3791.

Olson AK, Eadie BD, Ernst C, Christie BR (2006) Environmental enrichment and voluntary exercise massively increase neurogenesis in the adult hippocampus via dissociable pathways. Hippocampus 16:250-260.

Parent JM (2003) Injury-induced neurogenesis in the adult mammalian brain. Neuroscientist 9:261-272.

Rivers LE, Young KM, Rizzi M, Jamen F, Psachoulia K, Wade A, Kessaris N, Richardson WD (2008) PDGFRA/NG2 glia generate myelinating oligodendrocytes and piriform projection neurons in adult mice. Nat Neurosci 11:1392-1401.

Saigal S, Doyle LW (2008) An overview of mortality and sequelae of preterm birth from infancy to adulthood. Lancet 371:261-269.

Sale A, Maya Vetencourt JF, Medini P, Cenni MC, Baroncelli L, De Pasquale R, Maffei L (2007) Environmental enrichment in adulthood promotes amblyopia recovery through a reduction of intracortical inhibition. Nat Neurosci 10:679-681.

Scafidi J, Fagel DM, Ment LR, Vaccarino FM (2009) Modeling premature brain injury and recovery. Int J Dev Neurosci 27:863-871.

Schmitz C, Hof PR (2005) Design-based stereology in neuroscience. Neuroscience 130:813-831.

Seki T, Arai Y (1999) Temporal and spacial relationships between PSANCAM-expressing, newly generated granule cells, and radial glia-like cells in the adult dentate gyrus. J Comp Neurol 410:503-513.

Seri B, García-Verdugo JM, McEwen BS, Alvarez-Buylla A (2001) Astrocytes give rise to new neurons in the adult mammalian hippocampus. J Neurosci 21:7153-7160.

Sharp FR, Liu J, Bernabeu R (2002) Neurogenesis following brain ischemia. Brain Res Dev Brain Res 134:23-30.

Shors TJ, Townsend DA, Zhao M, Kozorovitskiy Y, Gould E (2002) Neurogenesis may relate to some but not all types of hippocampal-dependent learning. Hippocampus 12:578-584.

Soriano P (1999) Generalized lacZ expression with the ROSA26 Cre reporter strain. Nat Genet 21:70-71.

Vaccarino FM, Ment LR (2004) Injury and repair in developing brain. Arch Dis Child Fetal Neonatal Ed 89:F190-192.

van Praag H, Kempermann G, Gage FH (1999a) Running increases cell proliferation and neurogenesis in the adult mouse dentate gyrus. Nat Neurosci 2:266-270.

van Praag H, Christie BR, Sejnowski TJ, Gage FH (1999b) Running enhances neurogenesis, learning, and long-term potentiation in mice. Proc Natl Acad Sci U S A 96:13427-13431.

West MJ (1993) New stereological methods for counting neurons. Neurobiol Aging 14:275-285.

Yang Z, Levison SW (2006) Hypoxia/ischemia expands the regenerative capacity of progenitors in the perinatal subventricular zone. Neuroscience 139:555-564. 